\title{
Indícios de ilha de calor urbana em Sorriso/MT
}

Evidence of urban heat island in Sorriso/MT

\author{
Mauro Sergio de França'
}

'Professor de Geografia, Instituto Federal de Mato Grosso

\section{Resumo}

O objetivo deste estudo foi investigar indícios de ilha de calor em cidade de médio-porte no interior de Mato Grosso, Brasil. Para isso adotou-se a metodologia do transecto móvel para medidas diárias de temperatura e umidade relativa do ar em três horários distintos, durante episódios da estação chuvosa de 2013. Os resultados evidenciaram que a região central da cidade, apresentou mais aquecida e seca se comparado à periferia. Conclui-se que o uso do solo diferenciado no perímetro urbano contribuiu para essa constatação.

Palavras-chaves: Ilha de calor urbana; Sorriso/MT; Urbanização.

\begin{abstract}
The aim of this study was to investigate evidence of the heat island in mid-sized city in the interior of Mato Grosso, Brazil. For this we adopted the methodology of mobile transect for daily measurements of temperature and relative humidity at three times during episodes of the rainy season of 2013. Results showed that the central region of the city, had over heated and dry compared the periphery. We conclude that the use of different soil within the city limits contributed to this finding.
\end{abstract}

Keywords: Urban heat island; Sorriso/MT; Urbanization. 


\section{INTRODUÇÃO}

O sistema climático compreende o conjunto de interações físicas e químicas que ocorrem entre a atmosfera e a superfície da Terra, cujos resultados desempenham importante papel no estabelecimento do modelo de clima mundial. Nessas interações incluem-se tanto aquelas resultantes de forças naturais, quanto as que se dão devido à interferência das atividades antrópicas (Maitelli e Zamparoni, 2007).

Sob esse enfoque, estudos das interações entre as superfícies vegetadas e a atmosfera têm sido realizados no Brasil, sendo necessárias para a constatação de variações microclimáticas urbanas, entre elas a ilha de calor urbana - ICU. Esse fenômeno é conhecido como o acréscimo da temperatura do ar de regiões urbanizadas em relação às regiões rurais em seu entorno, em virtude da modificação e substituição de áreas de cobertura vegetal pela ocupação urbana e o excessivo adensamento das cidades (LI et al., 2009).

O expressivo crescimento populacional em Mato Grosso, especialmente entre as décadas de 1960 e 1991, quando a população sextuplicou, passando de 325 mil para 2,027 milhões de habitantes proporcionou o aumento dos estudos sobre a interferência da urbanização nas condições climáticas locais, sobretudo na capital (MACIEL et al., 2011; ALVES e BIUDES, 2012; FRANÇA, 2012; FRANCO et al., 2013, SANTOS, 2013; SANTOS et. al., 2013). Contudo, pesquisas relacionadas em áreas de expansão agrícola e pecuária onde o processo de desmatamento foi intenso nas últimas décadas são escassas, com destaque para os trabalhos de realizados por Zamparoni (1995), Sette (1996), Rosa (1999), Dourado (2000), Schreiner (2007), Dubreuil et al. (2010) e Gheno et al. (2012).

Nessa região de expansão agrícola destaca-se o município de Sorriso, localizado no médionorte mato-grossense considerado recentemente a "Capital Nacional do Agronegócio" (LF n ${ }^{\circ} 12.724$ de 16/10/2012). Essa atividade produtiva proporcionou um intenso crescimento na estrutura urbana que consequentemente originou microclimas diferenciados. Os componentes tipicamente utilizados na constituição do meio urbano tem maior capacidade de retenção de calor que os constituintes do meio rural. Assim, o armazenamento de calor no espaço construído associado à pequena perda de evaporação não faz com que o balanço de energia entre perdas e ganhos no ambiente seja nulo, criando condições para a formação da ICU (SANTOS et al., 2013).

Rocha e Fialho (2010) explicam que o efeito denunciador da alteração climática em escala local, causada em estruturas urbanas, é o aumento da temperatura do ar nas áreas centrais, principalmente em cidades de pequeno e médio porte que, começaram a apresentar, a partir da década de 1980, um crescimento urbano muito intenso. A ocupação do solo numa cidade é fundamentalmente caracterizada por elevada densidade edificada e área aberta pavimentada e impermeável, que contribui para o estabelecimento de um campo mais elevado de temperaturas. Quanto maior a densidade de construção e a ocupação do solo, maiores as atividades antrópicas, e, consequentemente, maior a captação e difusão da radiação solar e menor a ventilação no ambiente climático urbano (ROMERO, 2011).

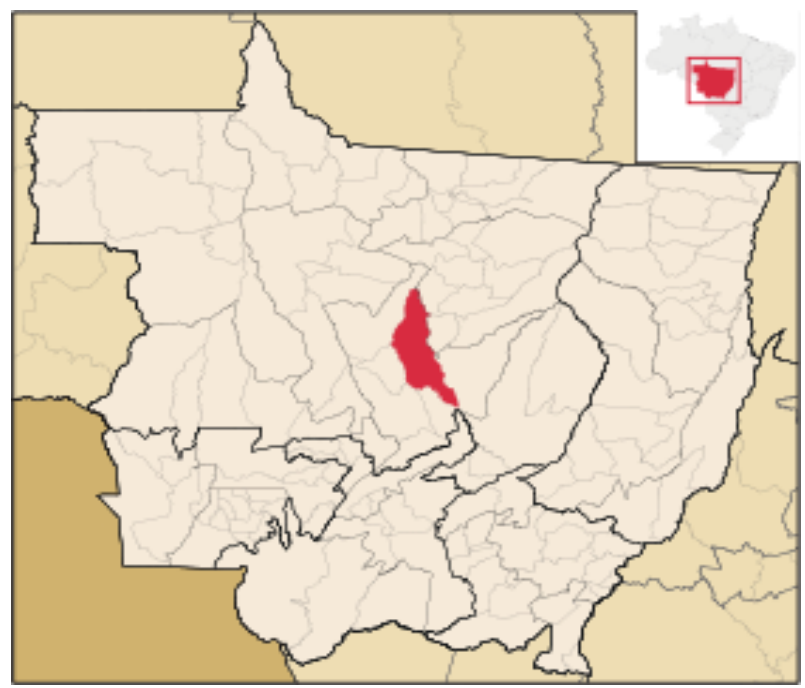

Figura 01 - Município de Sorriso/MT

Fonte: http://pt.wikipedia.org/wiki/Sorriso_(Mato_Grosso) 
O município localiza-se nas coordenadas $12^{\circ} 32^{\prime} 30^{\prime \prime} \mathrm{S}$ e $55^{\circ} 42^{\prime} 29^{\prime \prime} \mathrm{W}$, altitude média de $350 \mathrm{~m}$, mesorregião norte mato-grossense e na microrregião do Alto Teles Pires, com extensão territorial de $9.329,603 \mathrm{~km} 2$ (figura 1), fazendo limites com os municípios de Sinop, Vera, Nova Ubiratã, Santa Rita do Trivelato, Nova Mutum, Lucas do Rio Verde, Ipiranga do Norte e Tapurah (Ferreira, 2001).

O município tem relevo predominantemente plano da Chapada dos Parecis, com coberturas não dobradas do fanerozóico da bacia quaternária do Alto Xingu e solos são aluviais e Glei pouco Húmico, localizado na bacia do Teles Pires e clima Tropical quente e úmido, com quatro meses de seca, de maio a agosto, com temperatura média anual de $24^{\circ} \mathrm{C}$ e precipitação de $2.250 \mathrm{~mm}$. A cidade está situada no km 742 da rodovia federal BR 163, Cuiabá-Santarém, a cerca de $400 \mathrm{~km}$ da capital, Cuiabá. As principais atividades econômicas são a agricultura, a pecuária, o extrativismo vegetal, a agroindústria e o comércio (Ferreira, 2001)

\section{METODOLOGIA}

\subsection{Método e materiais}

O método adotado foi o transecto móvel conforme idealizado por Maitelli (1994). Nessa técnica as medidas móveis são realizadas com veículo automotor em movimento que possui sob o teto um termo-higrômetro acoplado em abrigo termométrico a $2 \mathrm{~m}$ do solo (figura 2). O percurso foi previamente definido $(26 \mathrm{~km})$, com 10 pontos de amostragem, cuja velocidade de deslocamento variou entre $30 \mathrm{e}$ $40 \mathrm{~km} / \mathrm{h}$ e duração média das coletas de 60 minutos.

A escolha do percurso considerou os eixos de expansão urbana, principalmente o eixo noroestesudeste e os diferentes usos do solo na região central. Os registros ocorreram em três dias da estação chuvosa de 2013 (04, 05 e 06/02) e em três horários (8h, 14h e 20h).

A instrumentação contou com o uso de um termo-higrômetro digital e portátil, marca J PROLAB (figura 3) com sensor de temperatura do ar e umidade relativa, com gradiente de temperatura interna e externa entre $-50^{\circ} \mathrm{C}$ a $70^{\circ} \mathrm{C}$; gradiente de umidade relativa entre $20 \%$ e $90 \%$, com exatidão de $+-1^{\circ} \mathrm{C}$ e $5 \%$; registros máximos e mínimos da temperatura e umidade e pilhas AA e um receptor GPS, marca Magellan Explorist 510 (figura 4) com câmera de 3.2 mega-pixel, compacto, 3 touch screen, mapa pré-carregado Word Edition e pilhas AA de 1,5 V. Os registros com as medições diárias foram tabulados em software Excel para posterior confecção de gráficos utilizados na discussão dos resultados.

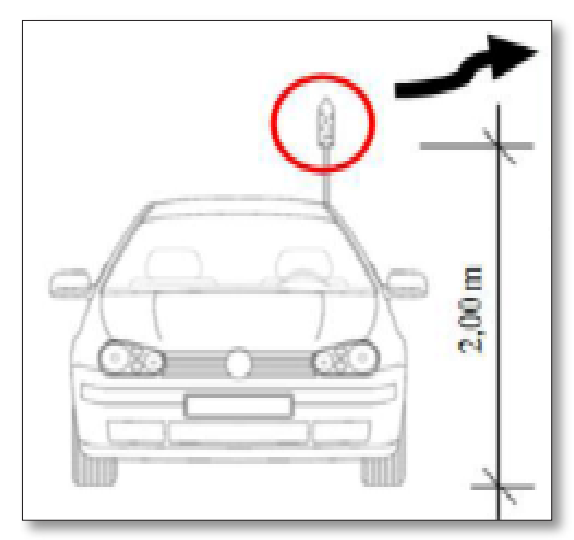

Figura 02 - Transecto

Adaptado: Santos et al.; (2013)

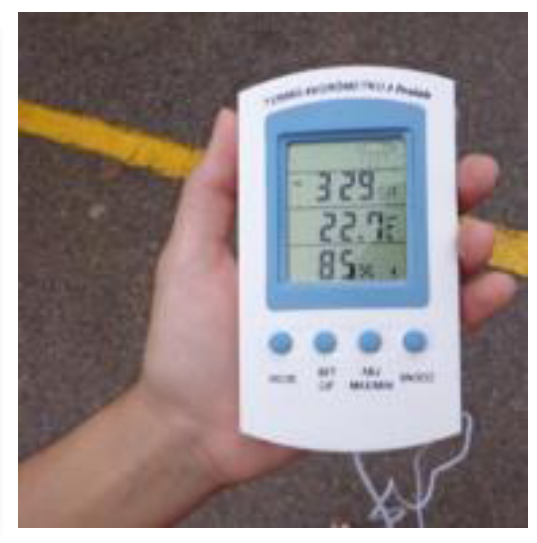

Figura 03 - Termo-higrômetro Foto: Autor

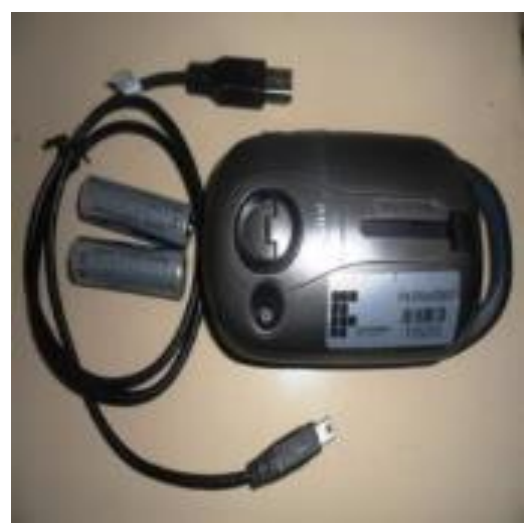

Figura 04 - Receptor GPS

Foto: Autor

\subsection{Caracterização dos pontos do transecto}

No perímetro urbano foram selecionados dez pontos amostrais com usos do solo diferenciados, conforme visualizado na figura 5. 


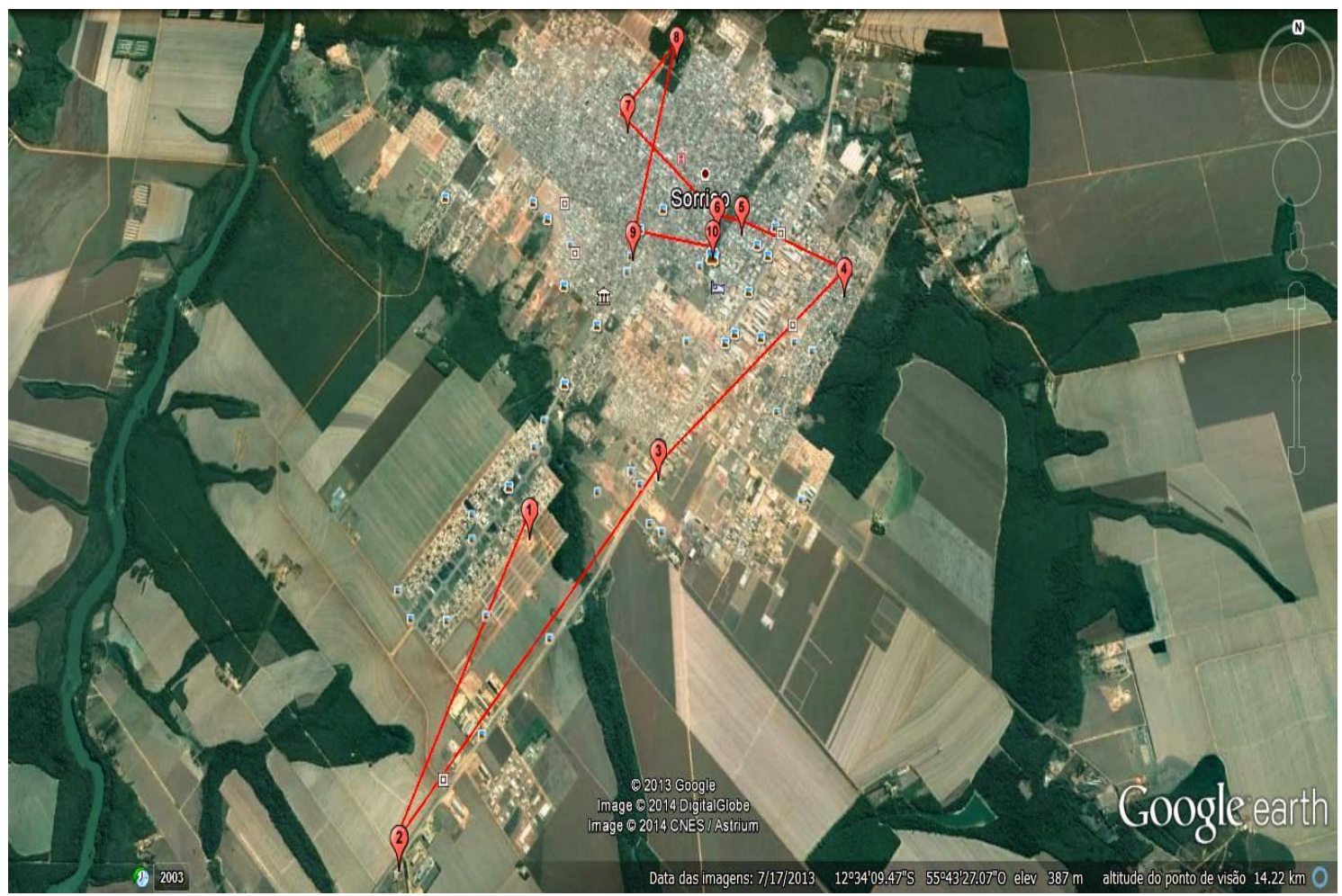

Figura 05 - Pontos e percurso do transecto no perímetro urbano de Sorriso

Fonte: Google Earth (2014)

Na tabela 1 são caracterizados (visitas in loco) os 10 pontos de amostragem do transecto embasados em Souza e Maitelli (2005) que foram utilizados na discussão dos resultados.

Tabela 1: Principais características do uso e ocupação do solo nos pontos selecionados.

\begin{tabular}{|c|c|}
\hline Pontos & Classes de uso e ocupação do solo \\
\hline $\begin{array}{l}\text { 5. Centro }\left(1^{\circ} 54^{\prime} 84^{\prime} ' S \text { e }\right. \\
\left.55^{\circ} 71^{\prime} 69^{\prime} ' W\right) \text {, altitude de } 377 \\
\text { m. } \\
\text { 10. Estacionamento da sede } \\
\text { atual do IFMT/Campus Sorriso } \\
\left(12^{\circ} 55^{\prime} 10^{\prime \prime} \text { e } 55^{\circ} 72^{\prime} 04^{\prime} ' W\right) \text {, } \\
\text { altitude de } 372 \mathrm{~m} \text {. }\end{array}$ & $\begin{array}{l}\text { Corredor Comercial (CC): O corredor comercial } \\
\text { apresenta áreas densamente ocupadas por construções } \\
\text { horizontais, com cobertura vegetal quase ausente, sendo } \\
\text { que a arborização viária é bastante limitada. Caracteriza- } \\
\text { se por ter intenso uso do solo, maior concentração de } \\
\text { atividades econômicas. Há predomínio de pavimentação } \\
\text { asfáltica (praticamente } 100 \% \text { e intenso e constante fluxo } \\
\text { de veículos e pedestres e escassez de vegetação. }\end{array}$ \\
\hline 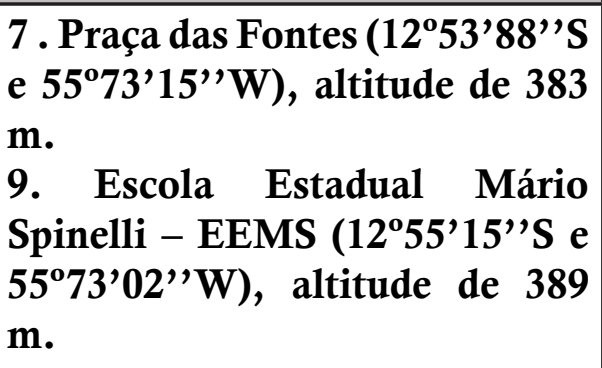 & $\begin{array}{l}\text { Alta Densidade Urbana (ADU): Áreas densamente } \\
\text { ocupadas por construções horizontais, com verticalização } \\
\text { quase nula. Caracteriza-se por apresentar densa } \\
\text { concentração de concretos, pavimentação asfáltica, maior } \\
\text { concentração de pedestres e de maior movimento no } \\
\text { trânsito, devido se concentrar próximo da área comercial, } \\
\text { expressão de máxima valorização do espaço. }\end{array}$ \\
\hline
\end{tabular}




\begin{tabular}{|c|c|}
\hline Pontos & Classes de uso e ocupação do solo \\
\hline 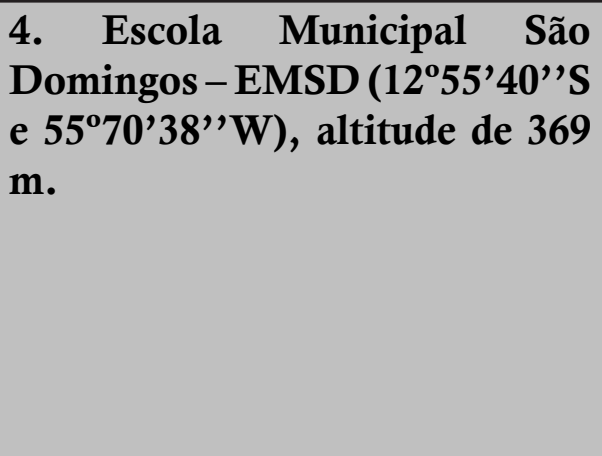 & $\begin{array}{l}\text { Média Densidade Urbana (MDU): Áreas em que } \\
\text { predominam as construções residenciais não muito } \\
\text { densas, afastadas umas das outras e onde o setor comercial } \\
\text { se restringe somente nas principais avenidas. Formada } \\
\text { por grandes bairros de classes sociais, média e baixa, } \\
\text { com várias ruas sem capeamento. Cobertura vegetal mais } \\
\text { densa, com árvores de grande porte nos quintais, praças, } \\
\text { calçadas e, principalmente em espaços vazios e margens } \\
\text { de córregos. }\end{array}$ \\
\hline $\begin{array}{l}\text { 2. Pátio do estacionamento do } \\
\text { Frigorífico de Aves Anhambi } \\
\left(12^{\circ} 60^{\prime} 47^{\prime} \text { 'S } 55^{\circ} 75^{\prime} 18^{\prime \prime} \mathrm{W}\right) \text {, } \\
\text { altitude de } 398 \mathrm{~m} \text {. } \\
\text { 3. Rodoviária Municipal } \\
\text { de Sorriso (12 } 57^{\prime} 18^{\prime \prime} \text { e e } \\
\left.55^{\circ} 72^{\prime} 63^{\prime \prime} \mathrm{W}\right) \text {, altitude } 386 \mathrm{~m} \text {. }\end{array}$ & $\begin{array}{l}\text { Baixa Densidade Urbana (BDU): Estas áreas estão } \\
\text { distantes do centro da cidade e passam a aparecer mais } \\
\text { na medida em que se caminha em direção à periferia } \\
\text { urbana, ou seja, são consideradas áreas periféricas ou } \\
\text { suburbanas da cidade. Há predomínio de lotes vazios em } \\
\text { relação às construções que são bem distantes umas das outras } \\
\text { e inúmeros galpões e barracões. Presença de muitas áreas } \\
\text { desocupadas. As ruas são, na maioria, de solo nu. São áreas } \\
\text { com cobertura vegetal na circunvizinhança e pastagens } \\
\text { em algumas áreas com características estritamente rurais. }\end{array}$ \\
\hline $\begin{array}{l}\text { 1. Terreno da futura sede do } \\
\text { Instituto Federal de Mato } \\
\text { Grosso/Campus } \\
\left.\text { (12 } 55^{\prime} 74^{\prime} \text { 'S e } 55^{\circ} 73^{\prime} 94^{\prime} ' \mathrm{~W}\right) \text {, } \\
\text { altitude de } 373 \mathrm{~m} \text {. }\end{array}$ & $\begin{array}{l}\text { Área Desmatada (AD): Foram áreas de vegetação nativa } \\
\text { que foram desmatadas para implantação de loteamentos, } \\
\text { ou até mesmo, destinadas a expansão urbana da cidade. } \\
\text { Localiza-se principalmente nas áreas verdes da cidade e } \\
\text { em alguns pontos isolados nas áreas de baixa densidade } \\
\text { urbana. Há presença de mata nativa na proximidade da } \\
\text { futura sede. }\end{array}$ \\
\hline $\begin{array}{l}\text { 6. Marco Zero }\left(12^{\circ} 54^{\prime} 85^{\prime} \text { 'S e }\right. \\
55^{\circ} 71^{\prime} 99^{\prime} \text { 'W), altitude de } 360 \\
\text { m. } \\
\text { 8. Parque Ecológico Municipal } \\
\left(12^{\circ} 53^{\prime} 09^{\prime} \text { 'S e } 55^{\circ} 73^{\prime} 57^{\prime} \text { 'W), }\right. \\
\text { altitude de } 355 \mathrm{~m} \text {. }\end{array}$ & $\begin{array}{l}\text { Área verde (AV): Compõem-se principalmente de matas ciliares } \\
\text { e de transição cerrado e floresta no centro e periferia, sendo que } \\
\text { neste último há uma área da representação semelhante a reserva } \\
\text { florestal. Dentro da cidade, estas áreas estão representadas } \\
\text { através da vegetação presente nos quintais, praças, caminhos } \\
\text { públicos e espaços vazios. }\end{array}$ \\
\hline
\end{tabular}

\section{RESULTADOS E DISCUSSÃO}

Os resultados obtidos com registros diários e horários da ICU foram discutidos tendo por base o trabalho por proposto por García (1996) que estabelece a magnitude desse fenômeno, ou seja, as diferenças térmicas formam ilhas de calor de fraca magnitude quando varia de $0^{\circ} \mathrm{C}$ a $2^{\circ} \mathrm{C}$, média magnitude quando varia de $2^{\circ} \mathrm{C}$ a $4^{\circ} \mathrm{C}$, forte magnitude quando varia de $4^{\circ} \mathrm{C}$ a $6^{\circ} \mathrm{C}$ e de muito forte quando superiores a $6^{\circ} \mathrm{C}$.

\subsection{Dos registros diários horários}

Os registros diários horários no período matutino mostraram que as temperaturas nos três dias e em todos os pontos variaram entre $22,7^{\circ} \mathrm{C}$, ponto 2 (BDU) dia 5 e $26,2^{\circ} \mathrm{C}$, ponto $6(\mathrm{AV})$ dia 6 , conforme a figura 6 . 


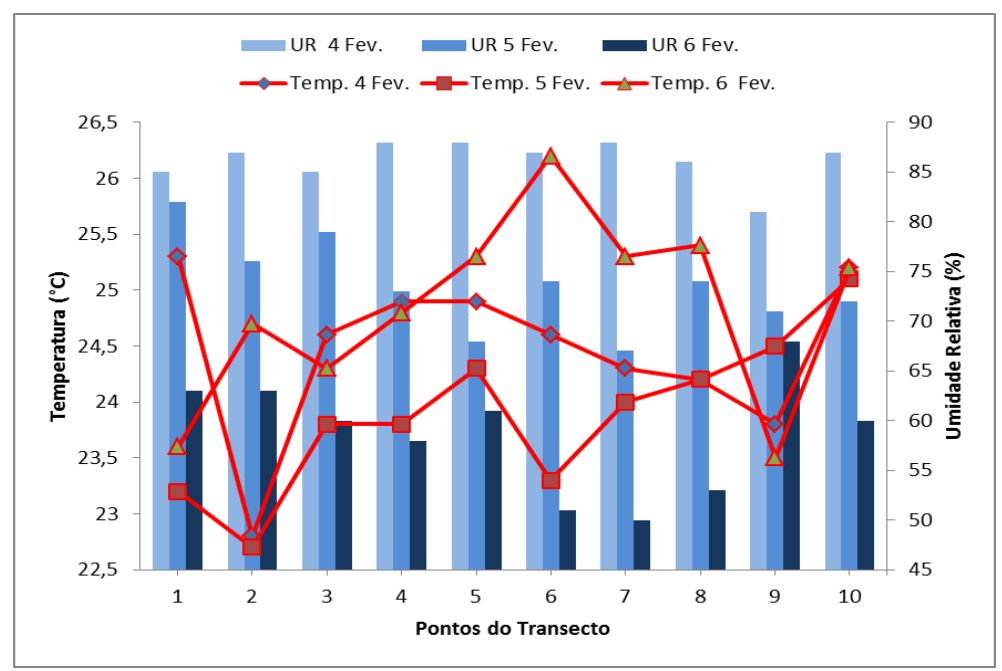

Figura 06 - Temperatura e umidade relativa do ar às $8 \mathrm{~h}$ Elaboração: Autor

A maior diferença térmica nesse período foi de $2,6^{\circ} \mathrm{C}$, entre o ponto $1(\mathrm{AD})$, com $23,6^{\circ} \mathrm{C}$ periferia, e o ponto $6(\mathrm{AV}) \operatorname{com} 26,2^{\circ} \mathrm{C}$ nas imediações do centro, no dia 6 , evidenciando ICU de média magnitude. A área verde nesse ponto é atravessada por duas grandes avenidas principais e duas marginais com trânsito intenso e excessiva urbanização que provavelmente influenciaram nessa constatação.

Santos (2013) explica que as mudanças provenientes da urbanização, como uso de materiais impermeáveis, aumento da rugosidade da superfície por meio da verticalização das edificações formandos os canyons urbanos tem importante contribuição na energia disponível no meio ocasionando anomalias climáticas, sendo a principal delas a formação de ICU, evidenciada nos registros de maiores temperaturas nas áreas mais urbanizadas, centro comercial da cidade, em relação às áreas periféricas com características ainda rurais.

A umidade relativa do ar nesse horário ficou entre 50\%, ponto 7 (ADU) no dia 6 e $88 \%$ nos pontos 4, 5, 7 (MDU, CC, ADU) no dia 4, dados esperados para a estação chuvosa, sobretudo devido à nebulosidade e intensas chuvas que ocorreram no período. Resultados semelhantes foram obtidos por Rosa (1999), Dourado (2000) e Gheno et al. (2012) em cidades importantes na mesorregião norte mato-grossense.

Os registros diários horários no período vespertino mostraram os maiores valores de temperatura, como esperado, variando entre $26,5^{\circ} \mathrm{C}$, no ponto 4 (MDU) no dia 6 e $36,8^{\circ} \mathrm{C}$, ponto 5 (CC) no dia 4 , conforme a figura 7.

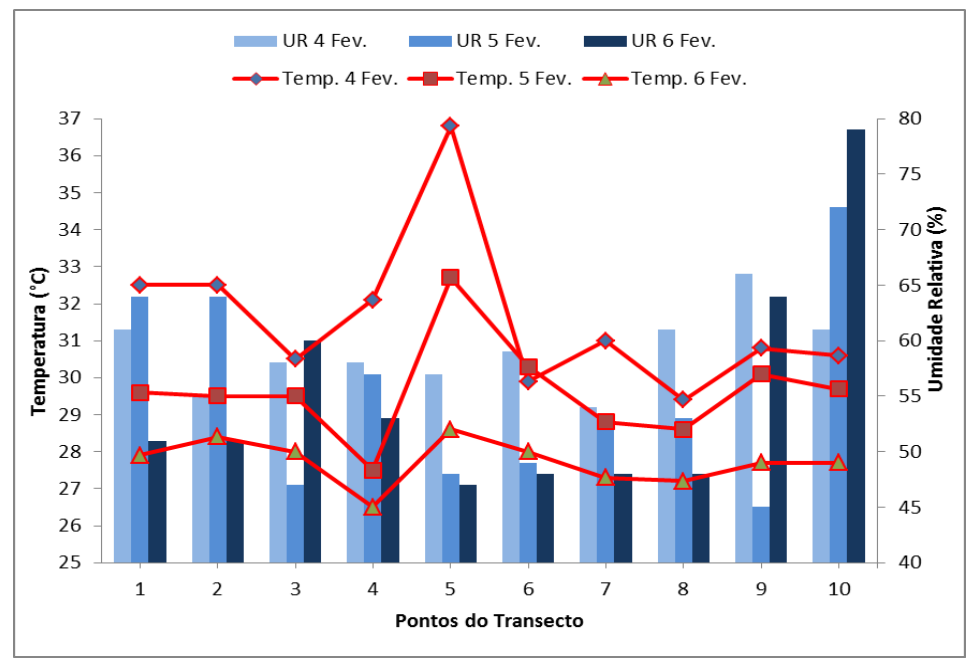

Figura 07 - Temperatura e umidade relativa do ar às $14 \mathrm{~h}$

Elaboração: Autor 
No dia 4 houve a maior diferença térmica entre as áreas, $7,4^{\circ} \mathrm{C}$, onde o ponto 5 registrou $36,8^{\circ} \mathrm{C}$ e o ponto $8(\mathrm{AV})$ apresentou $29,4^{\circ} \mathrm{C}$, evidenciando ICU muito forte em magnitude. Possivelmente esse fato tem relação com o uso do solo diferenciado entre esses ambientes, onde o entorno do centro (corredor comercial) é excessivamente pavimentado e impermeabilizado, apresentando intenso fluxo de veículos e de pessoas, enquanto o ponto 8 encontra-se em meio a uma mata nativa e densa arborização, com escassa movimentação de veículos. A taxa de umidade relativa no período variou entre $45 \%$ no ponto 9 (ADU) no dia 5 e $79 \%$ no ponto 10 (CC) no dia 6.

Nesse sentido, Alves e Biudes (2012) corroboram ao explicar que as áreas afastadas e com arborização proporcionam um arrefecimento da temperatura do ar e um acréscimo da umidade relativa. Alves et al. (2011) em estudo sobre a dinâmica de crescimento urbano na cidade de Anápolis/ GO verificou que o desconforto térmico é mais perceptível na área central devido à alta densificação de área impermeabilizada e construída, além do fato de haver maior circulação de pessoas e veículos.

Nessa discussão, Barbosa et al. (2003) em estudo sobre o clima urbano em Maceió/AL através de transectos, corroboram ao afirmar que a presença de vegetação influenciou alterando os resultados esperados no que tange aos valores da temperatura e da umidade relativa do ar, o que confirma o impacto positivo da vegetação urbana na melhoria das condições microclimáticas, principalmente na redução do rigor térmico, em cidades de clima quente e úmido, aliado à baixa latitude. Gomes e Amorim (2003) observaram em estudo em Presidente Prudente/SP que a vegetação é um importante componente regulador da temperatura urbana, pois absorve com muito mais facilidade a radiação solar que é utilizada nos seus processos biológicos: fotossíntese e transpiração.

Shams et al. (2009) ressalta que as áreas mais arborizadas das cidades, àquelas localizadas próximo aos grandes corpos d'água como os reservatórios tendem a apresentar temperaturas mais amenas, fazendo das fontes líquidas uma estratégia para prevenir futuros problemas de desconforto ambiental aliado à manutenção e/ou implantação de áreas verdes urbanas, com o propósito de mitigar o desconforto térmico sofrido pelos cidadãos nos espaços de socialização, seja ele, ambientes escolares e/ou praças públicas.

Barros e Musis (2013) ao analisar bairros da cidade de Cuiabá com transectos observaram que as menores temperaturas médias em quase todos os horários das estações estudadas foram encontradas no bairro mais arborizado, justificada pela presença de áreas verdes em quantidade e complexidade.

Siqueira et al. (2009) explicam que a presença de árvores é de fundamental importância, pois proporcionam conforto em todos os aspectos, trazendo sensação de conforto aos que estão no seu perímetro. Portanto, é praticamente consenso nos estudos que clima urbano, que a arborização urbana é uma das ferramentas mais eficaz para amenizar os rigores microclimáticos nas cidades e minimizar a ICU.

Os registros diários horários no período noturno mostraram as temperaturas variando entre $22,9^{\circ} \mathrm{C}$, no ponto $1(\mathrm{AD})$ no dia 4 e $27,3^{\circ} \mathrm{C}$ no ponto 4 (MDU) no dia 5 , conforme figura 8 .

A maior diferença térmica encontrada foi no dia 5 entre o ponto $4 \mathrm{com} 27,3^{\circ} \mathrm{C}$ e o ponto 8 (AV), com $25,6^{\circ} \mathrm{C}$, diferença de $1,7^{\circ} \mathrm{C}$ evidenciando indícios de ICU de fraca magnitude. Santos et al. (2013) ao estudar a cidade de Cuiabá em dois transectos com direções opostos às 20h, percebeu um perfil térmico que coincide com grande parte dos estudos realizados no período noturno, os quais registram na área mais densamente construída, um pico positivo de temperatura, comprovando-se a existência de ICU.

Nesse período os valores da umidade relativa ficaram entre $79 \%$ no ponto 2 (BDU) no dia 4 e 90\% no ponto 4 (MDU) no dia 6, valores típicos para a estação chuvosa. Barbosa e Amorim (2012) explicam que o período chuvoso no qual sistemas instáveis aliados às precipitações contribuem para menores diferenças térmicas nesse horário.

Para Maitelli (1994) o período noturno é o mais indicado para se observar a existência de ICU, principalmente pela ausência da radiação solar sob os ambientes. A autora explica que o período é o mais apropriado para avaliar se as diferenças de uso do solo interferem no microclima local, sobretudo porque as áreas mais densamente urbanizadas tendem a armazenar mais energia em forma de calor sensível (parcela da radiação líquida utilizada para o aquecimento do ar atmosférico) ao longo do dia e dissipar mais lentamente à noite, se comparadas às superfícies vegetadas.

Callejas (2012) corrobora ao explicar que o fluxo de calor antropogênico dissipado dentro do dossel urbano pela ação antrópica chega a representar 33\% da energia disponível no meio durante a noite, devido à supressão de radiação solar direta. Gomes e Lamberts (2009) em estudo sobre Mon- 
tes Claros/MG, após medições em três ciclos ao longo do ano de 2007 (quente e úmido, inverno e quente e seco) evidenciaram a formação da ICU nos três períodos medidos. Em geral, as diferenças de temperatura centro/periferia tendem a se estabelecer mais acentuadamente no período da tarde e prolongam-se até a noite, quando o fenômeno tem uma magnitude maior, embora a magnitude mais elevada neste estudo tenha ocorrido no período vespertino.

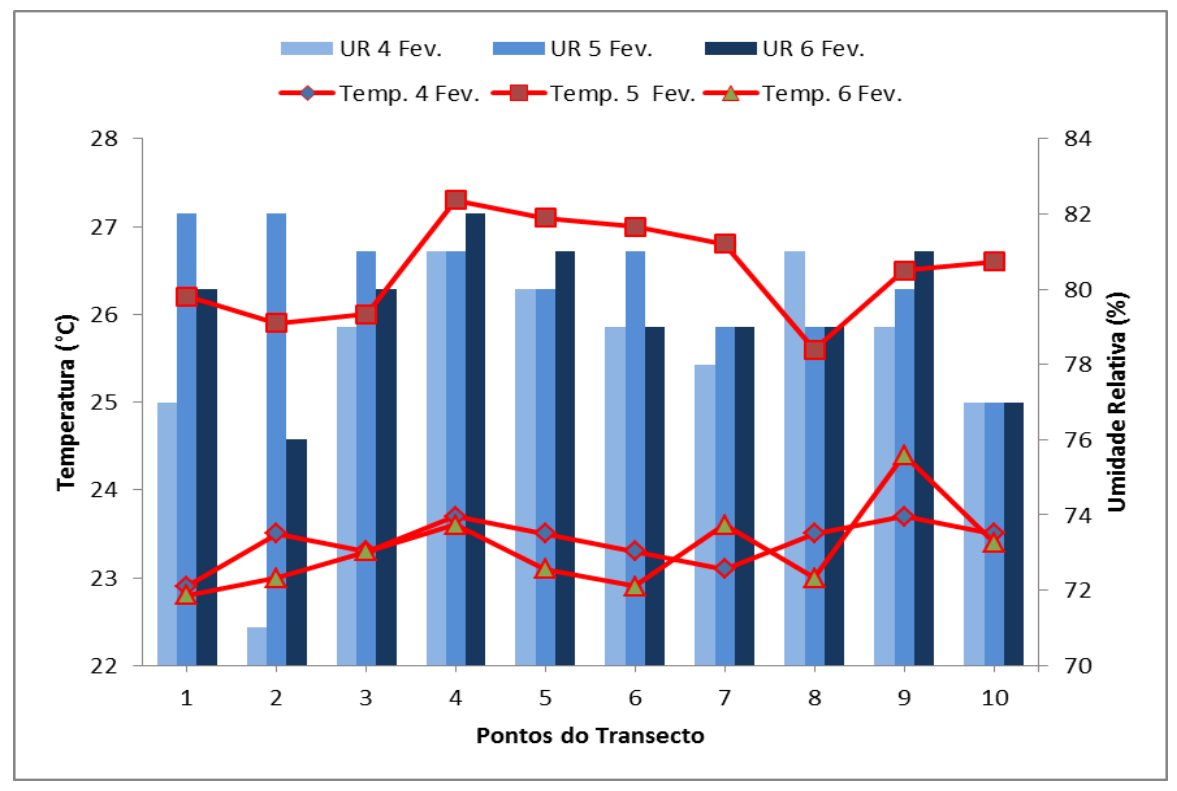

Figura 08 - Temperatura e umidade relativa do ar às $20 \mathrm{~h}$

Elaboração: Autor

\section{CONCLUSÃO}

Os resultados obtidos com as médias diárias horárias demonstraram indícios de ICU em Sorriso/MT, com magnitude entre fraca e muito forte. O uso do solo diferenciado no perímetro urbano foi determinante para essa evidência. A metodologia do transecto mostrou ser recomendável para esse tipo de experimento, embora seja prudente uma investigação mais duradoura e que inclua a estação seca na região.

\section{AGRADECIMENTOS}

Os autores agradecem ao PIBIC/IFMT e ao CNPq ao apoio financeiro e ao Campus Sorriso à disponibilidade do veículo para obtenção dos dados e desenvolvimento da pesquisa.

\section{REFERÊNCIAS}

ALVES, E.D.L. \& BIUDES, M.S. Padrões da temperatura do ar e da umidade relativa: Estudo de caso no campus de Cuiabá da Universidade Federal de Mato Grosso. Boletim Geográfico da UEM. Maringá, v.30, $\mathrm{n}^{\circ} 3$, p. 5-16, 2012.

ALVES, E.D.L. \& BIUDES, M.S. O uso do solo e as mudanças microclimáticas: Estudo de caso no campus de Cuiabá da Universidade Federal de Mato Grosso. Ateliê Geográfico. Goiânia. v.6, n², p. 95-111. Ago./2012.

ALVES, A.; ALVES, M.M.S.; AMARAL, A.L.M.; MORAIS, R.P. Dinâmica do crescimento urbano e padrões de ocupação do solo na formação de microclimas urbanos na cidade de Anápolis-GO. II Jornada de Ensino, Pesquisa e Extensão da UniEVANGÉLICA. Anais do IX Seminário de PIBIC e V Seminário de 
Extensão. v.1, Anápolis/GO, 2011.

BARBOSA, H.P. \& AMORIM, M.C.C.T. Clima urbano em Presidente Prudente/SP: Diferenças térmicas e higrométricas urbano/rural em episódios de outono. Revista Geonorte. Ed. Especial 2, v.2, n.5, p. 220 - 232 , 2012.

BARBOSA, R.V.R.; BARBIRATO, G.M.; VECCHIA, F.A.S. Vegetação urbana: Análise experimental em cidade de clima quente e úmido. ENCAC-COTEDI. Curitiba/PR. Nov. 2003.

BARROS, M.P. \& MUSIS, C.R. Análise implicativa para avaliar os aspectos que determinam a preferência por um bairro: o caso de Cuiabá/MT. RA'EGA. UFPR. nº.28, p.198-225. Curitiba/PR. 2013.

CALLEJAS, I.J.A. Avaliação temporal do balanço de energia em ambientes urbanos na cidade de Cuiabá-MT. Cuiabá. 265f. Tese (Doutorado), Programa de Pós-graduação em Física Ambiental, Universidade Federal de Mato Grosso, 2012.

DOURADO, S.C. Ilhas de calor e urbanização na Amazônia Mato-grossense. 2000. 92 p. Trabalho de Conclusão de Curso (Bacharelado em Geografia). Departamento de Geografia, Instituto de Ciências Humanas e Sociais, Universidade Federal de Mato Grosso. Cuiabá/MT, 2000.

DUBREUIL, V. \& DELAHAYE, C. Changements d'occupation du sol et leurs impacts climatiques au Mato Grosso, Brésil. França. Confins, 2010.

FERREIRA, J.C.V. Mato Grosso e seus municípios. Cuiabá: Secretaria de Estado de Educação, 2001.

FRANCO, F.M.; NOGUEIRA, M.C.J.A.; PINTO JÚNIOR, O.B.; BIUDES, M.S. NOGUEIRA, J.N. Traçado urbano e sua influência no microclima: Um estudo de caso em centro histórico. Revista Eletrônica em Gestão, Educação e Tecnologia Ambiental - REGET. v.9, nº9, p.1916-1931. Fev. 2013.

FRANÇA, M.S. Microclimas e suas relações com o uso do solo no entorno de escolas públicas na cidade de Cuiabá/MT. Anais do $4^{\circ}$ Simpósio de Geotecnologias do Pantanal. Bonito/MS. p. 282-288, out.2012.

FRANÇA, M.S.; MAITELLI, G.T.; NOGUEIRA, M.C.J.A. Variações microclimáticas no entorno de duas escolas públicas na cidade de Cuiabá/MT. Revista Eletrônica em Gestão, Educação e Tecnologia Ambiental REGET. v.15, nº15, p. 3012-3018. out. 2013.

GARCÍA, F. F. Manual de climatologia aplicada: clima, medio ambiente y planificación. Madrid: Editorial Síntesis, S.A., 1996. 285p.

GHENO, E.L.; FRANÇA, M.S.; MAITELLI, G.T. Variações microclimáticas na área urbana de Sinop, no final da estação chuvosa. Revista Educação, Cultura e Sociedade. Sinop/MT. v. 2, nº1, p. 139-153, jan./jul. de 2012.

GOMES, M.A.S. \& AMORIM. M.C.C.T. Arborização e conforto térmico no espaço urbano: Estudo de caso em praças públicas de Presidente Prudente/SP. Caminhos da Geografia. v.7, nº10, p. 94-106, set. de 2003.

GOMES, P.S. \& LAMBERTS, R. O estudo do clima urbano e a legislação urbanística: considerações a partir de Montes Claros/MG. Ambiente Construído. V.9, nº1, p. 73-91, Jan/Mar. de 2009.

IBGE. Instituto Brasileiro de Geografia e Estatística. Censo demográfico do Brasil. Rio de Janeiro, 2010.

IBGE. Instituto Brasileiro de Geografia e Estatística. Estimativa Populacional 2013. Disponível em: < http:// www.cidades.ibge.gov.br/> acesso em 26/02/2014.

LI, J.; WANG, X-R.; WANG, X-J.; MA, W.; ZHANG, H. Remote sensing evaluation of urban heat island. 
and its spatial pattern of the Shanghai Metropolitan Area, China. Ecological Complexity. v. 6, ed. 4, p. 413420, 2009.

MACIEL, C.R; NOGUEIRA, M.C.J.A; NOGUEIRA, J.S. Cobertura do solo e sua influência na temperatura de microclimas urbanos na cidade de Cuiabá/MT. Caminhos de Geografia. Uberlândia/MG, v. 12, n. 38, p. 40-57. set/2011.

MAITELLI, G. T. Uma abordagem tridimensional de clima urbano em área tropical continental: o exemplo de Cuiabá/MT. 1994. 204 p. Tese (Doutorado em Geografia), Departamento de Geografia, Faculdade de Filosofia, Letras e Ciências Humanas da Universidade de São Paulo, São Paulo/SP, 1994.

MAITELLI, G.T. \& ZAMPARONI, C.A.G.P. Expansão da soja na pré-Amazônia mato-grossense: Impactos Socioambientais. Entrelinhas: EdUFMT, Cuiabá/MT, 2007.

PRESIDÊNCIA DA REPÚBLICA. 2012. Lei Federal no 12.724, de 16 de outubro de 2012. Disponível em: <http://www.planalto.gov.br/ccivil/> acesso em 19/10/2013.

ROCHA, V.M. \& FIALHO, E.S. Uso da terra e suas implicações na variação termo-higrométrica ao longo de um transecto campo-cidade no município de Viçosa-MG. Revista de Ciências Humanas. v.10, n 1, p. 64-77, jan./jun. 2010.

ROMERO, M.A.B. Correlação entre o microclima urbano e a configuração do espaço residencial em Brasília. Fórum patrimônio: Mudanças climáticas e o impacto das cidades. Belo Horizonte/MG, v.4, nº 1, 2011.

ROSA, G.R. Clima urbano e o uso do solo na Amazônia Mato-grossense: o exemplo de Sinop. 1999. 60 p. Trabalho de Conclusão de Curso (Bacharelado em Geografia), Departamento de Geografia, Instituto de Ciências Humanas e Sociais da Universidade Federal de Mato Grosso, Cuiabá/MT, 1999.

SANTOS, F.M.M. Clima urbano de Cuiabá-MT-Brasil: Ocupação do solo e suas influências. Revista Monografias Ambientais - REMOA. UFSM, Santa Maria/RS. v.12, nº12, p.2749-2763. ago. 2013.

SANTOS, F.M.M.; NOGUEIRA, M.C.J.A.; MUSIS, C.R.; PINTO JÚNIOR, O.B.; NOGUEIRA, J.S. Influência da ocupação do solo no clima urbano de Cuiabá, Estado de Mato Grosso, Brasil. Brazilian Geographical Journal: Geosciences and Humanities research médium. Ituiutaba, v. 4, nº 1, p. 100-121, jan./jun. 2013.

SETTE, D. M. O clima urbano de Rondonópolis - MT. 1996. 137 p. Dissertação (Mestrado em Geografia Física). Faculdade de Filosofia, Letras e Ciências Humanas, Universidade de São Paulo, São Paulo, 1996.

SCHREINER, S. Um estudo preliminar das relações entre a expansão urbana e o clima de Alta Floresta/MT. 2007. 52 p. Trabalho de Conclusão de Curso (Bacharelado em Geografia) Departamento de Geografia, Instituto de Ciências Humanas e Sociais da Universidade Federal de Mato Grosso, Cuiabá/MT, 2007.

SHAMS, J.C.A; GIACOMELI, D.C.; SUCOMINE, N.M. Emprego da arborização na melhoria do conforto térmico nos espaços públicos livres. Sociedade Brasileira de Arborização Urbana. REVISBAU. Piracicaba/SP, v. $4, \mathrm{n}^{\circ} 4, \mathrm{p} .1-16,2009$.

SIQUEIRA, R.; QUEIROZ, F.; SOUSA, A.; TEIXEIRA, M. Clima urbano: Estudo climático da Praça Pedro II em Teresina/PI. In: IV Congresso de Pesquisa e Inovação da Rede Norte e Nordeste de Educação Tecnológica. Belém/PA, 2009.

SOUZA, S.C. \& MAITELLI, G.T. Mudanças climáticas na interface superfície atmosfera. Anais do X Encontro dos Geógrafos da América Latina. São Paulo, USP, mar 2005.

ZAMPARONI, C. A. G. P. Ilha de calor em Barra do Bugres e Tangará da Serra: uma contribuição ao estudo 
de clima urbano em cidades de pequeno porte em área tropical. 1995. 99 p. Dissertação (Mestrado em Geografia) Departamento de Geografia, Faculdade de Filosofia, Letras e Ciências Humanas da Universidade de São Paulo, São Paulo, 1995. 